BLS 35, No 1 2009. DOI: http://dx.doi.org/10.3765/bls.v35i1.3609

(published by the Berkeley Linguistics Society and the Linguistic Society of America)

\title{
Stress Dependent Vowel Reduction
}

\author{
HRAYR KHANJIAN \\ Massachusetts Institute of Technology
}

\section{Introduction}

In this paper, I examine a vowel reduction pattern in Western Armenian. The stressed and unstressed vowels of related forms in a paradigm present an interesting derived environment effect (DEE), where only destressed vowels undergo any change. Working in the framework of Optimality Theory (Prince and Smolensky 1993), I extend the application of Comparative Markedness (McCarthy 2003) to the phenomena in Armenian where the interaction between the phonotactics, faithfulness to vowel height and markedness against newly stressless vowels governs the surface forms of the language. A subset of the data reveals an interesting phonotactic restriction against the ...r.... sequence.

Section 1 presents the stress dependent vowel reduction data from Western Armenian and some relevant processes found in the language. Comparative Markedness and some relevant constraints are discussed in Section 2. In Section 3, I go through the analysis of all of the data. Reduction outside of Armenian is discussed in Section 4. Section 5 briefly presents stress shift off diphthongs and Section 6 concludes.

\section{Western Armenian}

Western Armenian is an Indo-European language spoken in major cities of the Middle East, Americas, Australia and Europe. I will be looking at how primary stress in Armenian affects the vowels in derived forms. Except for some adverbs and proper names lexical stress is assigned to the rightmost syllable of a prosodic word (Vaux 1998:132). When another morpheme is added to the right, stress shifts to the right as seen in (1).

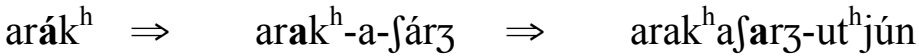

$$
\begin{aligned}
& \text { 'fast' } \Rightarrow \quad \text { 'fast moving' } \Rightarrow \quad \text { 'capability of moving fast' }
\end{aligned}
$$

Secondary stress is said to surface on the initial syllable, but this will not be investigated or considered in this paper since it does not seem to play a role in vowel reduction (Vaux 1998:134). 


\section{Stress Dependent Vowel Reduction}

\subsection{The Phenomena}

If the stressed vowel in the shorter word is a high vowel, $i$ or $u$, it either deletes (2a), surfaces as a schwa in the same location (2b) or surfaces as a schwa in a different location $(2 \mathrm{c})$ in the derived form. Other vowels do not undergo any change as seen in (3).

a. deletion: $\{[\mathrm{i}],[\mathrm{u}]\} \Rightarrow \varnothing$

$\begin{array}{llll}\text { mak }^{\mathrm{h}} \text { úr } & \text { 'clean' } & \text { mak }{ }^{\text {h}} \text {-él } & \text { 'to clean' } \\ \text { jergír } & \text { 'earth' } & \text { jergr-aJár3 } & \text { 'earthquake' } \\ \text { irigún } & \text { 'night' } & \text { irign-at ém } & \text { 'nighttime' }\end{array}$

b. schwa, same location: $\mathrm{C}_{1}\{\mathrm{i}, \mathrm{u}\} \mathrm{C}_{2} \Rightarrow \mathrm{C}_{1} \partial \mathrm{C}_{2}$

\begin{tabular}{|c|c|}
\hline $\mathrm{k}^{\mathrm{h}} \mathbf{i ́ n}$ & \\
\hline
\end{tabular}

c. schwa, different location: $\mathrm{C}_{1}\{\mathrm{i}, \mathrm{u}\} \mathrm{C}_{2} \Rightarrow \partial \mathrm{C}_{1} \mathrm{C}_{2}$

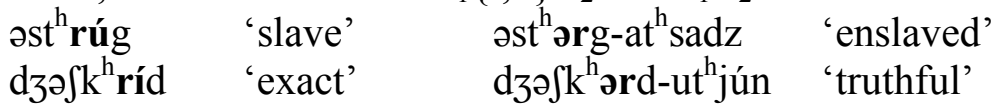

(3) [-high] vowels does not change

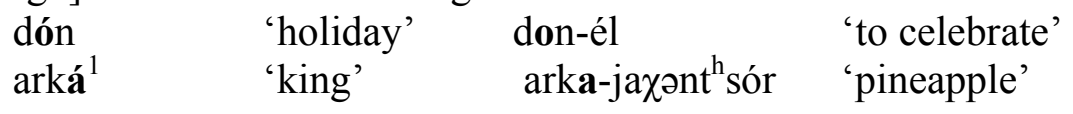

An important fact to point out is the derived environment effect, where stressless vowels in the base are not affected. Derived environment effects (DEE) is a cover term for a phonological process that applies only to environments that have undergone some other phonological change, therefore are said to be derived (Gnanadesikan 1997; Lubowicz 1999; McCarthy 2003 to name a few). This DEE is demonstrated in (4a-b) where only the high vowels that loose stress undergo any change. Therefore the word initial stressless [u] in (4a) or [i] in (4b) surfaces as is in the derived form. High vowels in positions that are never assigned stress like in bound morphemes $(4 \mathrm{c})$ or in the left nuclei of polysyllabic suffixes (4d) further demonstrate the restriction of reduction to only derived environments.
a. urá⿱
'happy'
urą-ut jún
'happiness'
b. irigún
'night'
c. ud-él
'to eat'
d. -ut 'jún '-ation'

$$
\text { irign-at ém 'nighttime' }
$$

\footnotetext{
${ }^{1}$ Armenian words can end in vowels, these vowels would be assigned the primary stress, but upon adding another morpheme this final vowel coalesces, deletes or remains depending on different factors, like vowel height, which will not be examined. I will be putting these cases aside.
} 
Hrayr Khanjian

Any analysis of Western Armenian should account for both the derived environment effect triggered by stress shift demonstrated above in (4) and all three repairs of high vowel reduction (2a-c), predicting all derived forms.

\subsection{Schwa Epenthesis and Phonotactics}

Since some of the schwas appear in a different location than the destressed high vowels as seen in (2c) and since Armenian exhibits an independent ə-epenthesis system it is relevant to ask what the phonotactic restrictions are on these schwas, since some of the schwas in the derived forms are possibly epenthetic instead of being reduced forms of the high vowels. Underlying consonant clusters are broken up by ə-epenthesis, as seen in (5) (Vaux 1998:66). The distribution of the schwa vowel is almost entirely predictable.

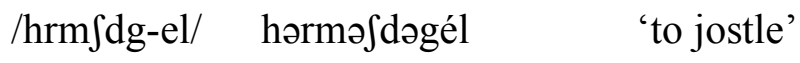

Here are a few relevant restrictions on the system. Every non-stop or non-affricate consonant needs to be adjacent to a vowel. Therefore forms like *[hrəmfədgel] with respect to [h] or *[hərm $\int d$ dəgel] with respect to [m] violate this photactic and

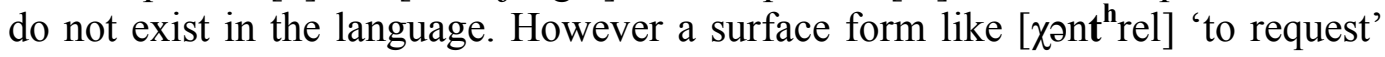
where a stop is not adjacent to a vowel is phonotactically sound. Since certain consonant clusters are phonotactically acceptable epenthesis applies minimally, being restricted by a markedness constraint like *a, and forms like *[hərəməSədəgel] do not surface. Roots that have a string of identical consonants, abab..., surface with the two substrings, ab, as identical to each other, in the same vein as aggressive reduplication (Zuraw 2002) as seen in (6):

$$
\begin{aligned}
& \mathrm{t}^{\mathrm{h}} \text { ərt }{ }^{\mathrm{h}} \text { ərél } \quad * \mathrm{t}^{\mathrm{h}} \text { ərt }{ }^{\mathrm{h}} \text { rel } \quad \text { 'to flutter' } \\
& \text { nert }{ }^{\mathrm{h}} \text { rúm *nert }{ }^{\mathrm{h}} \text { ərum 'investment' }
\end{aligned}
$$

The phonotactics of non-reduplicative roots do not surface with a schwa for a ... $\mathrm{t}^{\mathrm{h}} \mathrm{r}$... string, indicating that some form of aggressive reduplication is at play, specifically Zuraw's MAX-KK constraint: "If a word contains two substrings $\mathrm{S}_{1}$ and $S_{2}$ that are coupled, then every segment in $S_{1}$ must have a correspondent in $S_{2}$ and vice versa" (2002:404).

\section{Comparative Markedness}

As seen from the previous section, only the high vowels that bear stress in the base reduce. An example of this derived environment effect is reproduced in (7):

$$
\text { (7) irigún 'night' irign-at them 'during dusk' }
$$

A certain class of processes, of which Armenian DEE is a part of, are blocked unless their structural description is met either by morpheme concatenation or by prior rule application (Kiparsky 1973). A classic OT markedness constraint forces 


\section{Stress Dependent Vowel Reduction}

reduction of all (high) vowels and is not able to account for the derived environment effect presented above. We need to turn to a different markedness approach, namely Comparative Markedness (CM) (McCarthy 2003). In CM, the set of markedness constraints are split into New and Old; "a constraint violation is new if the corresponding material in the fully-faithful candidate (FFC) does not violate that constraint" (McCarthy 2003:6). The FFC is identical to the base.

(8) For example taking $* \mathrm{~V}_{[- \text {-stress }]}$ which is violated when a vowel is stressless:

a. [urá $\chi] \Rightarrow$ [ura $\chi u t^{\mathrm{h}}$ jún] ${ }_{\mathrm{N}} \mathrm{V}_{\text {[-stress] }}$ is violated with respect to [a].

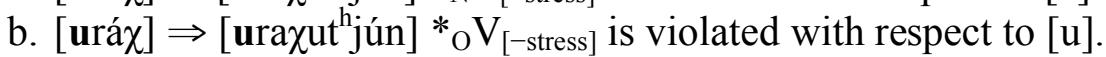

All the relevant faithfulness constraints evaluate surface forms and are therefore base-derivative (BD) constraints, unless otherwise stated. Since stress is assigned to the right most nuclei the ALIGN-STRESS-RIGHT constraint is ranked high in the system, which states that the primary stress of a prosodic word must appear on the final vowel. A newly stressless vowel is preferred over preventing a stress shift as seen from a simple example as in (9). Therefore the ranking AL-STR-RT $>>{ }_{N} \mathrm{~V}_{[- \text {-stress }}$ is revealed, where ${ }_{\mathrm{N}} \mathrm{V}_{[- \text {-stress] }}$ assigns a violation for every new instance of a stressless vowel, demonstrated in (8a).

bár 'dance' barél 'to dance'

The vowels of Armenian are not all affected by the shift of stress as presented above. Namely only the high vowels $\{[i],[\mathrm{u}]\}$ are affected. To drive the syncope of high vowels and restrict the deletion of non-high vowels, MAX-F, with respect to vowel height, must be at play in Armenian. More relevantly, MAX[-high] and MAX[+high] discussed by Casali (1997) must be ranked with respect to the markedness constraint ${ }_{N} \mathrm{~V}_{[- \text {-stress] }}$. MAX[-high] $>>{ }_{N} \mathrm{~V}_{[- \text {-stress] }}$ will ensure (10) and ${ }_{\mathrm{N}} \mathrm{V}_{[- \text {-stress }]} \gg \operatorname{MAX}[+$ high] will result in (11) drives syncope of high vowels. The ranking of MAX[-high] > MAX[+high] which falls out from transitivity is consistent with Casali (1997).

$$
\begin{array}{lll}
\text { MAx[-high] } & >*_{\mathrm{N}} \mathrm{V}_{[- \text {-stress }]}: & {[\text { bár }]+/ \mathrm{el} / \Rightarrow \text { barél *bərél }} \\
*_{\mathrm{N}} \mathrm{V}_{[- \text {-stress }]} & >\text { MAX[+high]: } & {[\text { dzúr }]+/ \mathrm{il} / \Rightarrow \text { dzəríl *dzuríl }}
\end{array}
$$

\section{Analysis}

In this section I will go through the three cases outlined above that need to be accounted for with respect to stress shift of high vowels. The $\mathrm{CM}$ constraint ${ }_{\mathrm{N}} \mathrm{V}_{[- \text {stress }}$ triggers three repairs summarized below in (12): 


\section{Hrayr Khanjian}

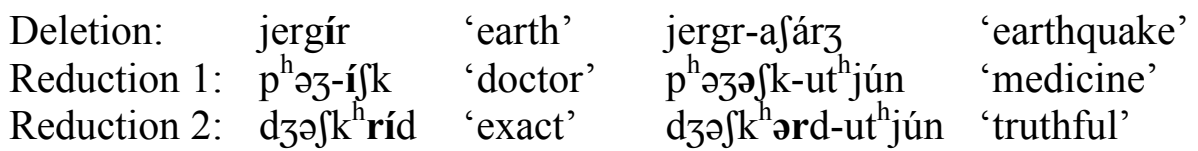

\subsection{Deletion Cases}

The destressed high vowels delete in the derived forms. The resulting consonant clusters are phonotactically sound and therefore schwas are not needed as seen from tableau (13).

\begin{tabular}{|c|c|c|}
\hline$[\mathrm{VCuCíC}]+/ \mathrm{VC} /$ & $*{ }_{N} \mathrm{~V}_{[- \text {stress }]}$ & $*_{\partial} \quad \operatorname{MAx}[+$ high $]$ \\
\hline VCuCiCV́C & $* !$ & \\
\hline $\mathrm{VCuCCV́} \mathrm{C}$ & & * \\
\hline VCuCəCV́C & $* !$ & $*$ \\
\hline VCəCCV́C & & $* ! *$ \\
\hline
\end{tabular}

\subsection{Reduction to Schwa: Schwa in situ}

In some cases the schwa is indispensable phonotactically as seen in the tableau (14) where the strict restriction against word initial complex onsets forces a $ə$ in the derived form:

[dzúr]+/il/ $\Rightarrow$ [dzəríl], ${ }^{*}[$ dzríl]
\begin{tabular}{|r||c|c|cc|}
\hline$[\mathrm{CúC}]+/ \mathrm{VC} /$ & $\mathrm{C} / / \mathrm{V}$ & ${ }_{N} \mathrm{~V}_{[- \text {stress }}$ & $*_{\partial}$ & $\mathrm{MAX}[+$ high $]$ \\
\hline \hline $\mathrm{CəCV́} C$ & & $*$ & $*$ & $*$ \\
\hline $\mathrm{CCV́} C$ & $* !$ & & & $*$ \\
\hline
\end{tabular}

However, we run into some trouble when considering the candidate that does not undergo any reduction, namely the most faithful candidate seen in (15):

[dzúr]+/il/ $\Rightarrow$ [dzoríl], *[dzuríl]
\begin{tabular}{|c|c|c|cc|}
\hline$[\mathrm{CúC}]+/ \mathrm{VC} /$ & $\mathrm{C} / / \mathrm{V}$ & ${ }_{N} \mathrm{~V}_{[- \text {stress }}$ & $*_{\partial}$ & $\mathrm{MAX}[+$ high $]$ \\
\hline \hline CuCV́C & & $*$ & & \\
\hline$\odot \mathrm{CəCV́} \mathrm{C}$ & & $*$ & $* !$ & $*$ \\
\hline
\end{tabular}

Tableau (15) reveals that ${ }_{N} \mathrm{~V}_{\text {[-stress] }}$ should not apply to all vowels, and should discriminate between $ə$ and $u$. To trigger reduction of the high vowel the two vowels must be categorically separate in the current system. Therefore reformulating the new $\mathrm{CM}$ constraint we get: ${ }_{\mathrm{N}} \mathrm{V}_{[- \text {-stress }]}$ which penalizes every instance of a newly stressless sonorous vowel. I assume a difference in sonority between the high vowels and schwa: i, u > , following de Lacy (2006). With this new formu- 
lation we get the following tableau in (16), where the most optimal candidate that ends up surfacing is the one with the $ə$ in place of the high vowel that was stressed in the base.

\begin{tabular}{|cr||c|c|cc|}
\hline & {$[\mathrm{CúC}]+/ \mathrm{VC} /$} & $\mathrm{C} / / \mathrm{V}$ & ${ }_{N} \mathrm{~V}_{[- \text {stress }]}$ & $*_{\partial}$ & $\mathrm{Max}[+$ high $]$ \\
\hline \hline a. & $\mathrm{CuCV́} C$ & & $* !$ & & \\
\hline b. & $\mathrm{C}$ CV́C & & & $*$ & $*$ \\
\hline c. & $\mathrm{CCV́} C$ & $* !$ & & & $*$ \\
\hline
\end{tabular}

\subsection{Reduction to Schwa: Schwa Off-Site}

In a third class of reduced forms the schwa in the derived form is not found in the same environment as the deleted high vowel in the base, demonstrated in (17). More specifically if an [r] segment precedes the high vowel in the base then it will follow the schwa in the derived forms:

\begin{tabular}{|c|c|c|c|}
\hline 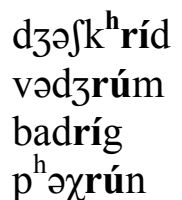 & $\begin{array}{l}\text { 'exact' } \\
\text { 'decision' } \\
\text { 'patrician' } \\
\text { 'brittle' }\end{array}$ & 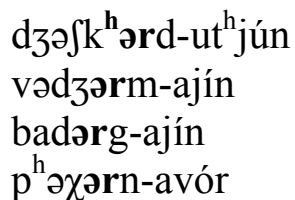 & $\begin{array}{l}\text { 'truthful' } \\
\text { 'like a decision' } \\
\text { 'like a patrician' } \\
\text { 'brittle-esque' }\end{array}$ \\
\hline
\end{tabular}

There are two paths to get from a base [...rí...] to a derived form [...ər...]. The first is a reduction path, where the high vowel reduces to schwa and a concurrent process of metathesis occurs, demonstrated in (18a). The second is one of deletion of the high vowel and a concurrent epenthesis of a schwa vowel before the [r] seen in $(18 b)$.

$$
\begin{aligned}
& \text { a. }\left[\ldots C r u ́{ }_{1} \mathrm{C}\right]+/ \ldots / \Rightarrow\left[\ldots \mathrm{C} \partial_{1} \mathrm{rC} \ldots\right] \\
& \text { b. }\left[\ldots \mathrm{Crú}{ }_{1} \mathrm{C}\right]+/ \ldots / \Rightarrow\left[\ldots \partial_{2} \mathrm{rC} \ldots\right]
\end{aligned}
$$

Two possibly relevant constraints at play here are the faithfulness constraints, DEP-ə, controlling the epenthesis of schwa, and LINEARITY, controlling metathesis. If DEP-a > LINEARITY then the optimal candidate is the one that has undergone metathesis as seen in (18a) and demonstrated by the tableau in (19):

\begin{tabular}{|c|c|c|c|}
\hline$\left[\ldots \mathrm{Crú}_{1} \mathrm{C}\right]+/ \mathrm{VC} /$ & $*_{\text {rə }} \quad *_{N} \mathrm{~V}_{[- \text {stress }]}$ & DEP-ə & LINEARITY \\
\hline$\ldots \mathrm{Cru}_{1} \mathrm{CV} C$ & *! & & \\
\hline$\ldots \mathrm{Cr}_{1} \mathrm{CV}_{\mathrm{C}}$ & $* !$ & & \\
\hline$\ldots \mathrm{Cr}_{2} \mathrm{CV} \mathrm{C}$ & $* !$ & * & \\
\hline d. $\ldots \mathrm{Cə}_{1} \mathrm{rCV} C$ & & & $*$ \\
\hline$\ldots \mathrm{C}_{2}{ }_{2} \mathrm{rCV} \mathrm{C}$ & & $* !$ & \\
\hline
\end{tabular}




\section{Hrayr Khanjian}

However, if LINEARITY >> DEP-ə then the optimal candidate is the one where the high vowel has deleted and a schwa has been epenthesized as in (18b) and seen below in (20):

\begin{tabular}{|c|c|c|c|c|}
\hline & $\left.\ldots \mathrm{Crú}_{1} \mathrm{C}\right]+/ \mathrm{VC} /$ & $*_{\mathrm{r} ə} \quad{ }^{*}{ }_{N} \mathrm{~V}_{[- \text {stress }]}$ & LINEARITY & DEP-ə \\
\hline a. & $\ldots \mathrm{Cru}_{1} \mathrm{CV́} C$ & $* !$ & & \\
\hline b. & $\ldots \mathrm{Cr}_{1} \mathrm{CV}^{\prime} \mathrm{C}$ & $* !$ & & \\
\hline c. & $\ldots \mathrm{Cr}_{2} \mathrm{CV} C$ & $* !$ & & * \\
\hline d. & .... $\partial_{1} \mathrm{rCV} C$ & & $* !$ & \\
\hline e. & $\ldots \mathrm{C}_{2} \mathrm{rCV} C$ & & & * \\
\hline
\end{tabular}

A way to determine which of the two paths Western Armenian takes is with wug words. Taking base forms like $\mathrm{VC}_{1} \mathrm{u}_{2} \mathrm{C}_{3} \#$ and $\mathrm{VC}_{1} \mathrm{C}_{2} \mathrm{u} \mathrm{C}_{3} \#$, we see where the schwas surface in the derived forms. If all the schwas surface in the same locations as the original high vowels then there would be strong evidence for the reduction analysis, therefore the metathesis path as in tableau (19). However if what is underlying the system is in fact deletion and epenthesis then the a would not be driven by the location of the high vowel in the base and would always appear in the same position in the derived forms, pointing to the ranking in tableau (20). Preliminary testing with minimally contrasting wug words of the forms $\left\{\ldots \mathrm{VC}_{1}\{\dot{u}, i\} \mathrm{C}_{2} \mathrm{C}_{3} \#, \ldots \mathrm{VC}_{1} \mathrm{C}_{2}\{\dot{\mathrm{u}}, 1\} \mathrm{C}_{3} \#\right\}$ indicates that when $\mathrm{C}_{2}$ is $[\mathrm{r}]$, the derived forms of either wug word of a pair surface with a [ə] before the [r]. When $\mathrm{C}_{2}$ is any other segment, the overwhelming majority of the derived forms surface with the [ə] in the position of the original high vowel environment. Therefore the system in WA at this juncture seems to be a mixture of deletion/epenthesis, when $[\mathrm{r}]$ is $\mathrm{C}_{2}$, and reduction, for all other $\mathrm{C}_{2}$ segments.

The results of the wug test and the available related forms in the lexicon reveal a high ranked phonotactic restriction in Western Armenian where instead of a ...rə... string, a ...ər... sequence surfaces regardless of the base position of the high vowel. I have represented this with the markedness constraint *ro seen in the above tableaux (19) and (20). To figure out the exact nature and motivation of this constraint investigation into the phonetics of the interacting segments might help. Also other constraints or approaches should be explored at this point to figure how to account for this restriction.

Another obstacle in the Western Armenian phonological system is the high front rounded vowel [y] which does not reduce when stress shifts off of it like the two other high vowels [i] and [u], as see in (21):

$$
\text { k у́ь 'village' } \quad \mathrm{k}^{\mathrm{h}} \text { ук-abéd 'chieftain' }
$$

This non-reduction is unexpected since [y] is [+high] like [i] and [u]. Relevant formants and length of $[y]$ are similar to the other two high vowels and reduction 


\section{Stress Dependent Vowel Reduction}

is expected. As we saw [i] and [u] change, so why would [y] not change? A likely explanation can be found in how this vowel is produced by different speakers. I am currently conducting some experiments examining the phonological nature of this nucleus in Western Armenian. The initial observation of the fluidity in production might be due to exposure of Western Armenian speakers to the other dialects, since most Eastern Armenian dialects realize these nuclei as [ju]. Western Armenian speakers can sometimes produce [y] as [ju] or [uj] depending on the word. I will put the non-reduction of $[\mathrm{y}]$ aside for the time being.

In this section I have presented a Comparative Markedness approach to the derived environment effect found in Western Armenian. The constraint against newly stressless sonorous vowels, ${ }_{\mathrm{N}} \mathrm{V}_{[- \text {-stress }]}$ is at play. The derived forms that surface with schwas in the same location as the destressed high vowels correspond back to the base high vowels. While the forms where the schwa surfaces in a different position, forms involving the segment $[\mathrm{r}]$ point to a deletion/epenthesis analysis where the ə does not correspond back to the base vowel as seen with a wug test. Now I will briefly mention what happens in other languages that exhibit vowel reduction patterns and move onto the diphthongs.

\section{Reduction Outside Armenian}

Reduction alternations are common cross-linguistically. First, languages like Romanian (22), Palauan (23) and Yakan exhibit phenomena of derived environment effects of stressless vowel reduction, as was seen in Western Armenian where only a certain set of vowels are affected by stress shift.

In Romanian, [á $] \Rightarrow[\Lambda]$ when stress shifts (Steriade 2008):
a. surák
'poor'

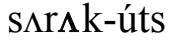
'poor-dim'
b. papúk 'slipper'
paputf-él, *p^putf-él
'slipper-dim'

In Palauan all destressed short vowels delete or reduce to ə (Zuraw 2003:3):
a. osíb
osp-ú-k
'pick'
b. bilás
biləs-n-él, *bələs-n-él
'boat'

Armenian has a phonological process of ə-epenthesis as demonstrated above, which differentiates it from Romanian and Yakan. Therefore in Armenian, surface schwa could be either a reduced vowel or an epenthetic vowel. According to Flora (1984) Palauan also has a phonological process of o-epenthesis, evidenced from surface glottal stops. Further investigation needs to be conducted to figure out the most accurate phonological description of Palauan and how the epenthesis would interact with the reduction/deletion. Putting Palauan aside, Armenian, just like Romanian and Yakan can be accounted for using CM (Steriade 2008).

Other languages exhibit vowel reduction across the board. For example in Catalan, Bulgarian and Russian vowel contrasts collapse in unstressed positions. In Catalan for example there are seven vowels that can surface in stressed positions, $\{\mathrm{i}, \mathrm{e}, \varepsilon, \mathrm{a}, \mathrm{o}, \mathrm{o}, \mathrm{u}\}$, while only three are found in unstressed positions, $\{\mathrm{i}, \mathrm{u}$, 


\section{Hrayr Khanjian}

ə) (Crosswhite 2000). The Comparative Markedness analysis can be extended to the languages where vowels in both destressed and never stressed positions reduce. Instead of just the ${ }^{*} \mathrm{~V}_{\text {[-stress }]}$ constraint being ranked above a specific faithfulness constraint, the ${ }^{*} \mathrm{~V}_{\text {[-stress }]}$ will also be ranked higher. This will result in a general reduction of stressless vowels.

\section{Reduction of [uj]}

A final case of reduction that is related to stress is that of the diphthongs. The diphthong [uj] reduces to [u] when stress shifts off of it as seen in (24a). The reduction of the diphthong is accomplished by the deletion of the glide. Whereas no other diphthong reduces as seen from (24b).

\begin{tabular}{|c|c|c|c|}
\hline $\begin{array}{l}\text { a. hújs } \\
\text { məJagújt }{ }^{\mathrm{h}} \\
\mathrm{k}^{\mathrm{h} u ́ j \mathrm{j}}\end{array}$ & $\begin{array}{l}\text { 'hope' } \\
\text { 'culture' } \\
\text { 'color' }\end{array}$ & 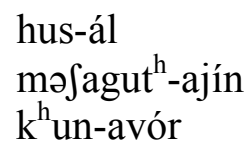 & $\begin{array}{l}\text { 'to hope' } \\
\text { 'cultural' } \\
\text { 'colorful' }\end{array}$ \\
\hline 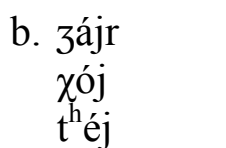 & $\begin{array}{l}\text { 'boulder' } \\
\text { 'ram' } \\
\text { 'tea' }\end{array}$ & $\begin{array}{l}\text { zajr-ód } \\
\text { xoj-anál } \\
\text { th }^{\text {ej-níg }}\end{array}$ & $\begin{array}{l}\text { 'rocky' } \\
\text { 'to attack' } \\
\text { 'tea pot' }\end{array}$ \\
\hline
\end{tabular}

Putting the reduction of the high vowels together with the paradigm presented in (24) the chain shift $u j>u>\varnothing$ is revealed. This chain shift cannot be accounted for with classical OT markedness. Any markedness constraint that would trigger the reduction of [uj] to [u] would be better satisfied with the complete deletion of [uj] instead of reduction to [u]. There is a large literature on chain shifts and I will not go into the details of each proposed addition to OT. These phenomena are found in a number of languages, such as Arabic (McCarthy 2003), Tonkawa (Gouskova 2003), Palauan (Zuraw 2003), Nzebi (Kirchner 1996), Polish (Lubowicz 2003)...

I will account for this chain shift using a distantial faithfulness constraint, DIST[mora] $\leq 1$ (Zuraw 2003). This constraint restricts alterations of more than one mora between two corresponding nuclei. In other words two corresponding nuclei can differ by at most one mora. I assume that $ə$ does not carry a mora, since it cannot bare stress. The rest of the monophthongs carry one mora and the diphthongs carry two. One other constraint active in this system is WSP (Weightto-Stress-Principle (Prince \& Smolensky 1993)), which triggers reduction of the diphthong. This constraint requires the heaviest nuclei of a word to be stressed, weight in terms of number of moras. Both DIST[mora] $\leq 1$ and MAX[+high] must be ranked above WSP in this system as shown in (25):

$$
\begin{array}{ll}
\text { DIST }[\text { mora }] \leq 1>\text { WSP } & {\left[\mathrm{t}^{\mathrm{h}} \text { sájn]+/avor/ } \Rightarrow \mathrm{t}^{\mathrm{h}} \text { sajnavór, * * } \mathrm{t}^{\mathrm{h}}\right. \text { sənavór }} \\
\text { MAX }[+ \text { high }]>\text { WSP } & {\left[\mathrm{t}^{\mathrm{h}} \text { sájn]+/avor } / \Rightarrow \mathrm{t}^{\mathrm{h}} \text { sajnavór, } * \mathrm{t}^{\mathrm{h}}\right. \text { sanavór }}
\end{array}
$$

The non-reduction of non-high diphthongs is seen with tableau (26). 
Stress Dependent Vowel Reduction

(26)

\begin{tabular}{|c|c|c|c|}
\hline$\left[\mathrm{Ca}_{1} \mathrm{j} \mathrm{C}\right]+/ \mathrm{VC} /$ & $\operatorname{DIST}[\mathrm{MOR}] \leq 1 \quad$ AL-STR-RT & $\operatorname{Max}[+$ hi $]$ & WSP \\
\hline CajCV́C & & & * \\
\hline CaCV́C & & $* !$ & \\
\hline CájCVC & $* !$ & & \\
\hline $\mathrm{C}_{1} \mathrm{CV} C$ & *! & * & \\
\hline
\end{tabular}

The mechanism that prevents the reduction of [aj] is MAx[+high]. The glide in the diphthongs is specified for height, namely [+high]. When the glide is deleted and the other segment in the nuclei is [-high], the [+high] feature deletes and incurs a MAX[+high] violation, demonstrated in (27b). This is not the case for [uj], where the [+high] feature is preserved on the reduced [u], (27a):
(a) $\quad[+$ high $] \Rightarrow[+$ high $]$
$\mathrm{k}^{\mathrm{h}} \widehat{\mathrm{u}]} \quad[\mathrm{j}] \mathrm{n} \quad \stackrel{\mathrm{k}}{\mathrm{h}}[\mathrm{u}] \mathrm{n} \ldots$

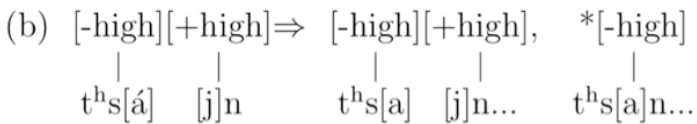

Now turning to the reduction of [új], the system reduces the diphthong to [u], as revealed by tableau (28) below.

\begin{tabular}{|c|c|c|c|c|c|}
\hline \multicolumn{2}{|c|}{$\left[\mathrm{Cu}_{1} \mathrm{j} \mathrm{C}\right]+/ \mathrm{VC} /$} & $\operatorname{DIST}[\mathrm{MOR}] \leq$ & $*[+\mathrm{voc}] / / \mathrm{\partial}$ & $\operatorname{MAx}[+\mathrm{hi}]$ & \multirow{2}{*}{$\begin{array}{c}\text { WSP } \\
* !\end{array}$} \\
\hline a. & CujCV́C & & & & \\
\hline b. & $\mathrm{CuCV} C$ & & & & \\
\hline c. & $\mathrm{C}_{1} \mathrm{j}_{\mathrm{C}} \mathrm{CV}^{\mathrm{C}}$ & & $* !$ & & \\
\hline d. & $\mathrm{C}_{1} \mathrm{CV}^{\mathrm{C}} \mathrm{C}$ & $* !$ & & * & \\
\hline e. & $\mathrm{C}_{2} \mathrm{CV́C}$ & $* !$ & & * & \\
\hline
\end{tabular}

As seen from the above tableau MAX[+high] is not violated by the surface form (28b) since a high segment from the base diphthong [uj], namely [u] is present in the derived form.

\section{Conclusion}

Examining the stressed and unstressed vowels of related forms of Western Armenian, it becomes clear that a process of destressed vowel reduction exists, where potentially deletion and epenthesis work together to get the desired forms of some of the paradigms. High vowels that once bore stress do not undergo an across the board reduction to $\partial$, but delete whenever the resulting consonant cluster is phonotactically acceptable. In the framework of Optimality Theory, specifically Comparative Markedness, I have been able to account for the derived environment effect data of Western Armenian. Romanian and Yakan derived environment effects are also accounted for with $\mathrm{CM}$. Therefore we have a unified account for these effects that now includes Western Armenian. 
Hrayr Khanjian

\section{References}

Casali, Rod F. 1997. Vowel elision in hiatus contexts: Which vowel goes? Language 73(3):493-533.

Crosswhite, Katherine. 2000. Sonority-driven reduction. In Lisa Conathan, Jeff Good, Darya Kavitskaya, Alyssa Wolf, and Alan C. Yu, eds., Proceedings of the $26^{\text {th }}$ Annual Meeting of the Berkeley Linguistics Society, 77-88. Berkeley, CA: Berkeley Linguistics Society.

de Lacy, Paul. 2006. Markedness: Reduction and preservation in phonology. Cambridge: Cambridge University Press.

Flora, Jo-Ann. 1984. Schwa in Palauan. In Byron Bender, ed., Studies in Micronesian linguistics, 149-164. Pacific Linguistics C-80. Canberra: Research School of Pacific and Asian Studies, Australian National University.

Gnanadesikan, Amalia. 1997. Phonology with ternary scales. Ph.D. diss., Department of Linguistics, University of Massachusetts, Amherst.

Gouskova, Maria. 2003. Deriving economy: Syncope in Optimality Theory. Ph.D. diss., Department of Linguistics, University of Massachusetts, Amherst.

Kiparsky, Paul. 1973. Abstractness, opacity and global rules. In O. Fujimura, ed., Three dimensions of linguistic theory, 57-86. Tokyo: TEC.

Kirchner, Robert. 1996. Synchronic chain shifts in Optimality Theory. Linguistic Inquiry 27(2):314-350.

Lubowicz, Anna. 1999. Derived environment effects in OT. In N. Kimary, S. Shahin, Susan J. Blake, and Eun-Sook Kim, eds., Proceedings of the $17^{\text {th }}$ West Coast Conference on Formal Linguistics, 451-465. Stanford, CA: CSLI.

Lubowicz, Ania. 2003. Counter-feeding opacity as a chain shift effect. In G. Garding and M. Tsujimura, eds., Proceedings of the $22^{\text {nd }}$ West Coast Conference on Formal Linguistics, 315-327. Somerville, MA: Cascadilla Press.

McCarthy, John. 2003. Comparative markedness. Theoretical Linguistics 29:1-51.

Prince, Alan, and Paul Smolensky. 1993. Optimality Theory: Constraint interaction in generative grammar. Technical Report RuCCS-TR-2. New Brunswick, NJ: Rutgers University Center for Cognitive Science. [Revised version available online as ROA-537 at http://roa.rutgers.edu.]

Steriade, Donca. 2008. Contour correspondence: The segmental evidence. Paper presented at the $11^{\text {th }}$ International Symposium on Chinese Languages and Linguistics, National Chiao Tung University, Taiwan.

Vaux, Bert. 1998. The phonology of Armenian. New York: Oxford University Press.

Zuraw, Kie. 2002. Aggressive reduplication. Phonology 19:395-439.

Zuraw, Kie. 2003. Vowel reduction in Palauan reduplicants. In A. R. N. Richards. ed., Proceedings of the 8th Annual Meeting of the Austronesian Formal Linguistics Association [AFLA 8], 385- 398. Cambridge, MA: MIT Working Papers in Linguistics. 
Hrayr Khanjian

Massachusetts Institute of Technology

Department of Linguistics and Philosophy, 32D-808

77 Massachusetts Avenue

Cambridge, MA 02139

khanjian@mit.edu 